\title{
Home delivery of medication as part of reducing congestion in primary healthcare in Tshwane District Health Services
}

\author{
J M Louw, ${ }^{1}$ MB ChB, DTM\&H, MMed (Fam Med), PhD Fam Med; B Rantloane, ${ }^{2}$ B Cur, B Cur Hons; S Ngcobo, ${ }^{1}$ BCMP, MPH; \\ Z Brey, ${ }^{3}$ MB ChB, MBA, PhD; J Hugo, ${ }^{1}$ MB ChB, MFamMed; D Basu, ${ }^{4}$ MB ChB, MMed (Public Health); J Wishnia, ${ }^{5}$ MPH; \\ C Christian, ${ }^{6}$ BSC (Physio), PhD Economics; M Pitsi, ${ }^{2}$ MPM; M Makhudu, ${ }^{2}$ B Dent Ther, MPH; S Seane, ${ }^{7}$ MB ChB, MBA; \\ M Lukhele, ${ }^{8}$ MBBS, MMed (Ortho) \\ ${ }^{1}$ Department of Family Medicine, School of Medicine, Faculty of Health Sciences, University of Pretoria, South Africa \\ ${ }^{2}$ Tshwane District Health Services, Gauteng Department of Health, South Africa \\ ${ }^{3}$ Global Health Senior Program Officer, Bill and Melinda Gates Foundation, Johannesburg, South Africa \\ ${ }^{4}$ Department of Public Health Medicine, Steve Biko Academic Hospital and University of Pretoria, COPC Research Unit, Department of Family Medicine, \\ Faculty of Health Sciences, University of Pretoria, South Africa \\ ${ }^{5}$ Centre for Health Policy, School of Public Health, Faculty of Health Sciences, University of the Witwatersrand, Johannesburg, South Africa \\ ${ }^{6}$ Department of Economics, University of the Western Cape, Cape Town, South Africa \\ ${ }^{7}$ Health and Social Development Department, City of Tshwane Metropolitan Municipality, South Africa \\ ${ }^{8}$ Gauteng Department of Health, Johannesburg, South Africa
}

Corresponding author: J M Louw (murray.louw@up.ac.za)

Background. Congestion at health facilities poses the risk of extensive spread of the severe acute respiratory syndrome coronavirus 2 (SARSCoV-2) to patients at high risk for severe illness and death due to this infection. During the lockdown to control the spread of the virus, many patients with chronic conditions are not visiting health facilities and not collecting their chronic medication. To improve adherence to medication, home delivery of medication was instituted for patients with chronic diseases who had been receiving care at the Skinner Street Clinic in Tshwane.

Objective. To support patients with chronic diseases who were unable to collect their medication, by remotely consulting (telehealth) and delivering their medication during the lockdown due to the COVID-19 pandemic.

Methods. Patients were identified for potential home delivery of medication from the clinic appointment book. Their files were retrieved, and they were telephoned and offered the option of receiving medication through home delivery instead of attending a health facility. For those who qualified and accepted home delivery, files were sent to the clinic pharmacy. Medication parcels were prepared and sent to ward-based outreach teams to deliver to patients. Relevant information was captured on the Qualtrics platform.

Results. A total of 1727 files were evaluated. Of these patients, 60\% were on treatment for HIV infection, and 19\% for hypertension. A total of $32 \%$ ( $n=547$ ) were eligible for home delivery of medication, but only $25 \%$ of the 1727 patients accepted the home delivery of medication. Almost 25\% could not be contacted. Compared with those with non-communicable diseases (NCDs) or a combination of HIV and one or more NCDs, a higher proportion of HIV-positive patients with no other diagnosis chose not to have their medication delivered at home. Patients using the service expressed their appreciation and requested that it be extended to others.

Conclusion. Home delivery of medication has significant advantages for patients. It can ensure that patients continue to adhere to their chronic medication in the midst of the COVID-19 epidemic, without increasing their risk of contracting the virus. Expanding the home delivery of medication to more facilities while aligning it with the Centralised Chronic Medicine Dispensing and Distribution programme has the potential to alleviate the congestion and workload of primary care facilities while these are under severe pressure owing to the COVID-19 pandemic.

South Afr J Pub Health 2020;4(2):50-55. https://doi.org/10.7196/SHS.2020.v4.i2.124

In the context of the current COVID-19 pandemic, congested public health facilities pose a health risk to patients with chronic conditions such as non-communicable diseases (NCDs), HIV/AIDS and tuberculosis (TB). Recent medical research articles and reports indicate that patients with chronic conditions have relatively high mortality when infected by the severe acute respiratory syndrome coronavirus 2 (SARS-CoV-2). ${ }^{[1-3]}$ During the various alert levels of the COVID-19 lockdown, some chronic patients did not risk going to clinics for collection of their usual medications, and adherence levels dropped substantially. ${ }^{[4]}$ In addition, transport options were limited, and up to $11 \%$ of patients on chronic medication in cities, and $25 \%$ from informal settlements, struggled to access care. ${ }^{[5]}$ 


\section{RESEARCH}

Tshwane District in Gauteng Province has a population of 3275152 people, $80 \%$ of whom rely on public healthcare services, which are offered through 76 primary healthcare (PHC) clinics and community health centres $(\mathrm{CHCS})$ situated in the district. ${ }^{[6]}$ Tshwane District Hospital has been turned into a COVID-19 hospital, and as a result, the Skinner Street PHC clinic situated on the same premises has been closed. In 2019/2020, the PHC headcount for the clinic was 58 147. The clinic serves largely the Tshwane inner city population living in high-density housing. ${ }^{[7]}$ Services from the clinic were moved to neighbouring PHC facilities such as the FF Ribeiro and Folang clinics in subdistrict 3 of the Tshwane Health District.

The Tshwane Health District and City of Tshwane (local government), in partnership with the University of Pretoria, have been working with the Bill and Melinda Gates Foundation on a project to implement home delivery of medication, similar to Project Last Mile Delivery and Operation Phuthuma, since April 2020, and realised its appropriateness to address the current situation faced by the Gauteng Department of Health as a result of the lockdown.

Tshwane Health District already uses a service called Centralised Chronic Medicine Dispensing and Distribution (CCMDD), which pre-packages medication and allows patients to collect their medication at convenient pick-up sites. However, during the lockdown, some of those sites were closed. Some of the CCMDD pick-up points are within PHC clinics - patients can skip the queue and collect their medication (called Fastlane pick-ups) at the clinic pharmacy. Many patients were unable to collect chronic medication from both the internal (Fastlane) and external CCMDD pick-ups, as well as from the usual PHC clinic pharmacy services during the lockdown. Therefore, patients enrolled for the home delivery pilot project were both CCMDD and non-CCMDD users.

The purpose of the current project is to improve access to chronic medications through home delivery, while also decongesting medical facilities. It provides optional alternative access to patients who miss follow-up consultations or medication collection visits. The home delivery also includes a health promotion and prevention check, including screening for TB and COVID-19. By enrolling in this project, patients do not need to attend health facilities as regularly, thereby reducing their risk of exposure to COVID-19.

The project is therefore designed to support patients with chronic diseases who are unable to collect their medication during the lockdown owing to the COVID-19 pandemic, by remote consulting (telehealth) and delivering medication.

\section{Methods}

The project used action research methodology to address a service delivery problem, using a collaborative approach among the partners mentioned above. Chronic patients who attended Skinner Street Clinic were included in the study. Excluded were patients due for special investigations (e.g. follow-up blood tests) or who needed to be physically examined in a face-to-face consultation. In addition, patients residing outside the delivery area, and those who declined home delivery of medication, were also excluded.

Prior to the rollout of the project, the team worked on setting up the necessary systems to allow medications to be transported and delivered to patients' homes. These included creating standard operating procedures (SOPs) for telephone calls to patients to assess clinical appropriateness and willingness, packaging of medication and use of Uber transport to collect medication from the clinic pharmacy and take it to community health workers (CHWs) within communities. The SOPs also included measures to safeguard medication from being lost or stolen, and ways to protect drivers and CHWs from COVID-19. Fig. 1 shows the steps undertaken from enrolment through to final delivery.

Fig. 2 shows the overarching steps described in Fig. 1 in graphic format, including the potential reach of the project (1 800 CHWs in the district).

The files of those patients who could not be contacted initially were marked as such, and when they attended a neighbouring clinic, their phone numbers were verified and they were offered the option to leave the queue, return home and have their medication delivered to them the next day.

\section{Ethical approval}

The study was granted ethical clearance from the Research Ethics Committee of the Faculty of Health Sciences, University of Pretoria (ref. no. 102/2011).

\section{Results}

The project is in its pilot phase, and below we outline the results descriptively to showcase its reach and the potential impact if it went to scale.

Table 1 describes the 1727 files that were evaluated for inclusion in the project. Within the files evaluated, 357 patients had more than 1 diagnosis, 302 had 2 diagnoses, 48 had 3 and 7 had 4 diagnoses. Therefore, there were 2146 instances of medical conditions identified within the 1727 files.

Of the 1727 patients:

- almost one-third (547 patients, 32\%) were immediately suitable for home delivery

- 757 (44\%) required further investigation or in-person check-up and were not suitable for home delivery

- 379 (22\%) could not be reached via telephone (voicemail or no answer)

- 44 (3\%) did not have a correct contact number.

\begin{tabular}{|c|c|}
\hline Conditions & Patients, $n(\%)^{*}$ \\
\hline HIV & $1284(74)$ \\
\hline Hypertension & $418(24)$ \\
\hline Mental health-associated conditions & $105(6)$ \\
\hline Diabetes mellitus & $98(6)$ \\
\hline Dyslipidaemia & $61(4)$ \\
\hline Pregnancy-related conditions & $56(3)$ \\
\hline Osteoarthritis & $30(2)$ \\
\hline Asthma & $26(2)$ \\
\hline Epilepsy & $17(1)$ \\
\hline Other & $51(3)$ \\
\hline
\end{tabular}




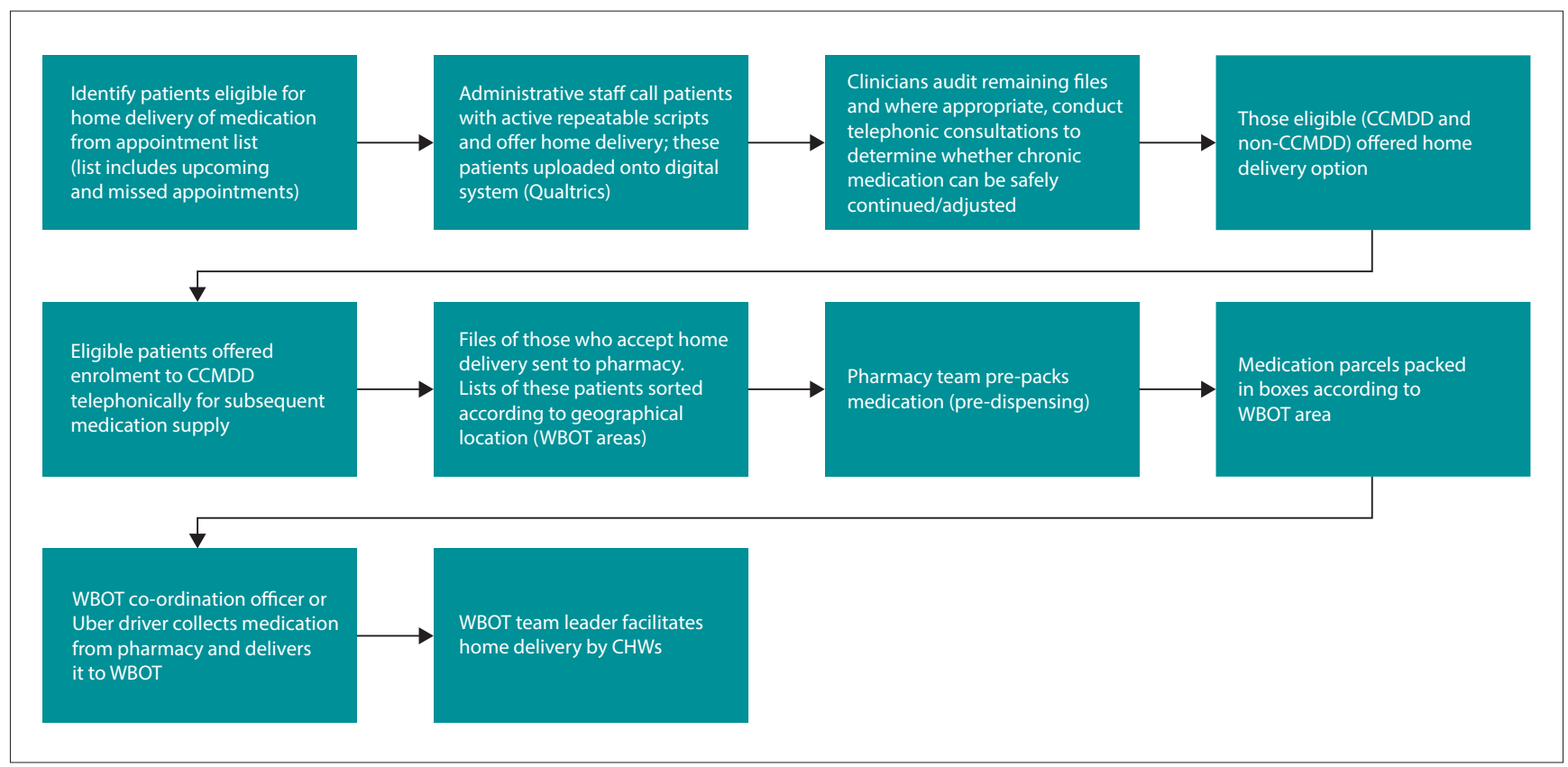

Fig. 1. Project steps. (CCMDD = Centralised Chronic Medicine Dispensing and Distribution system; WBOT = ward-based outreach team; $C H W=$ community health worker).

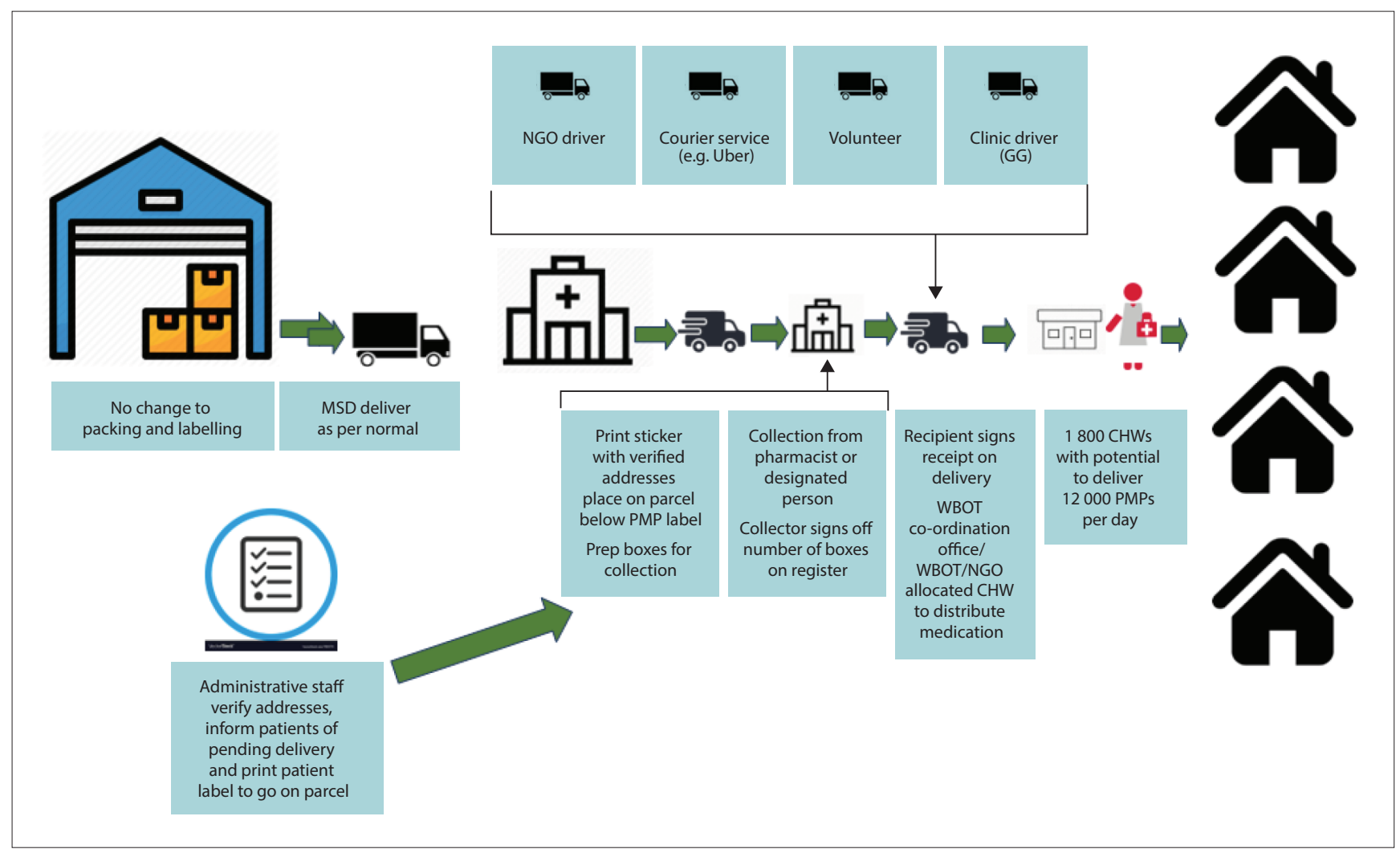

Fig. 2. Home delivery project. (MSD = medicines supply depot; $N G O=$ non-governmental organisation, $G G=$ government garage vehicle; $P M P=$ patient medicine parcel; $W B O T=$ ward-based outreach team; $C H W=$ community health worker.)

Of the 547 who qualified for home deliveries, 432 (79\%) accepted home deliveries, and 115 (21\%) of the patients did not (Fig. 3).

The 432 (25\% of the total 1727 ) patients who qualified for and agreed to receive home deliveries had the conditions listed in Table 2. Of these 432 patients, 102 had more than 1 diagnosis, 84 had 2 diagnoses, 14 had 3 diagnoses and 4 had 4 diagnoses.

Four patients included in the project also needed to be referred for further management at a health facility, and 54 (13\%) enrolled 


\section{RESEARCH}

in the CCMDD programme. Ten (2\%) of the 432 were already enrolled.

Table 3 shows the reasons that 757 patients (44\%) did not qualify for home delivery.

Fig. 4 shows the medical conditions of those who chose to opt in $v$. those who refused the service. The figure shows that those with HIV alone were the most likely to refuse the service $(n=85)$. This could be due to stigma associated with HIV in the community.

Qualitatively, the project received positive feedback, which was collected via the Qualtrics platform at the point of delivery:

'Highly appreciated service, I am so happy, they look after our health.'

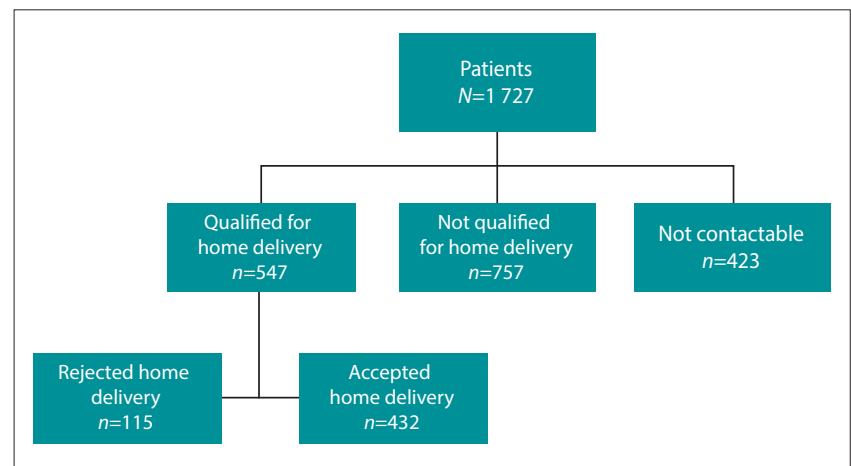

Fig. 3. Steps to final inclusion group.

$\begin{array}{ll}\text { Table 2. Conditions of patients included in project ( } \mathbf{N}=\mathbf{5 5 9} \\ \text { conditions in } \mathbf{4 3 2} \text { patients) } \\ \text { Conditions } & \text { Patients, } \boldsymbol{n} \text { (\%)* } \\ \text { HIV } & 281(65) \\ \text { Hypertension } & 148(34) \\ \text { Diabetes mellitus } & 27(6) \\ \text { Mental health-associated conditions } & 24(6) \\ \text { Dyslipidaemia } & 22(5) \\ \text { Osteoarthritis } & 18(4) \\ \text { Asthma } & 11(3) \\ \text { Epilepsy } & 6(1) \\ \text { Other } & 18(4) \\ { }^{*} \text { Total }>100 \% \text { because } 102 \text { patients had }>1 \text { condition. } & \end{array}$

$\begin{array}{ll}\text { Table 3. Reasons for exclusion from project } & \\ \text { Reason for exclusion } & \text { Patients, } \boldsymbol{n} \text { (\%) } \\ \text { Referral for face-to-face consultation } & 281(37) \\ \text { Due for routine blood tests } & 230(30) \\ \text { Stays outside delivery area } & 108(14) \\ \text { Pregnancy-related conditions } & 55(7) \\ \text { Given treatment elsewhere } & 29(4) \\ \text { Viral load unsuppressed } & 22(3) \\ \text { Newly diagnosed } & 13(2) \\ \text { Already enrolled on CCMDD } & 6(1) \\ \text { Other } & 13(2) \\ \text { Total } & 757(100) \\ \text { CCMDD = Centralised Chronic Medicine Dispensing and Distribution programme. }\end{array}$

'I am very happy with what health department is doing for us, they are taking care of us. I was worried how I was going to get to clinic, thanks a lot to the staff members.'

'Patient very happy with treatment home delivery system, requests that we should also deliver medication for his wife.'

'I was very scared of going out because of COVID-19, I am very happy.'

The feedback showed not only acceptance of the new patientcentric option, but those who were enrolled were eager to get other family members enrolled too.

The project used several mechanisms to deliver medication (Fig. 2). The Uber option was mainly used for those patients who lived further away from the clinic. On 21 May the first Uber delivery was completed successfully to the homebased care office in central Tshwane. The next day, delivery expanded to Mamelodi. Five (2\%) of the 432 deliveries failed initially due to the patients not being at the delivery address. These were successfully delivered on the second attempt after rearranging the time or location of delivery telephonically with the patients.

\section{Discussion}

This pilot serves as encouragement, and provides data, for decisions around whether to expand this community-oriented primary careand telehealth-related intervention to more facilities and districts.

The Western Cape Department of Health, in partnership with Aviro, uses WhatsApp and unstructured supplementary service data (USSD) to enable patients to provide their latest, most accurate contact details. ${ }^{[8]}$ Implementing such a system in Gauteng would enhance cost-efficiency, particularly if patients also indicate, through such system, their willingness or otherwise to receive medication by delivery at home. Clinicians would then waste less time evaluating files and making phone calls to patients who do not answer the call or do not agree to receive medication by home delivery.

Patients on antiretroviral (ARV) medication without an additional diagnosis were less likely to accept home delivery of medication than those on treatment for NCDs, or for a NCD as well as HIV. This may be due to concerns that their HIV diagnosis could be revealed

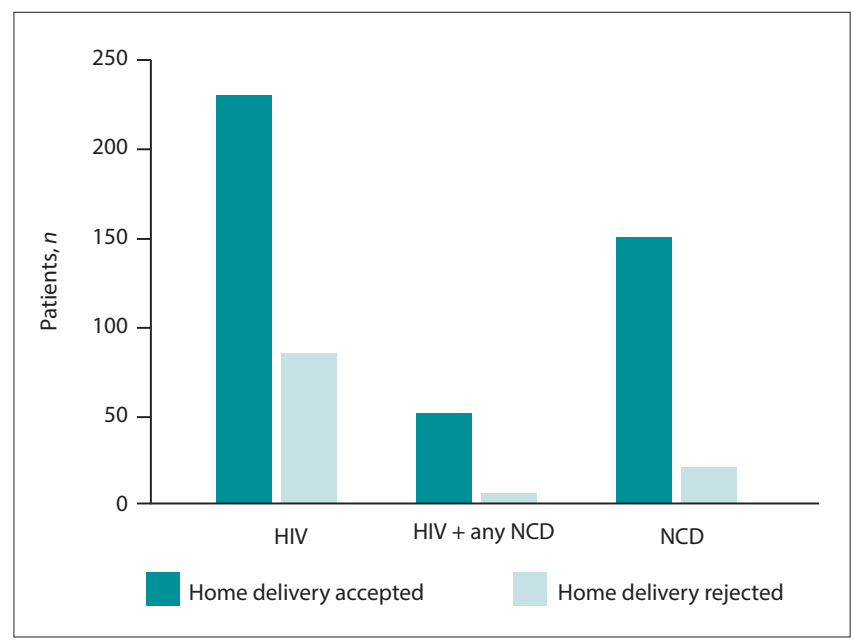

Fig. 4. Comparison between those who accepted and those who refused the service, by disease profile ( $N=547)$. (NCD = non-communicable disease). 
to others in their household when ARVs are delivered to their homes. This unwillingness may therefore be an indirect indication of the fear of stigmatisation, and of patients' non-disclosure of their HIV diagnosis. Other factors affecting acceptance or otherwise of the home delivery option may be the patient's age, or the perceived risk of COVID-19.

We believe the project has the following advantages:

(i) Patients have the opportunity to continue life-saving medical treatment without risking exposure to COVID-19.

(ii) Patients have significant cost savings in terms of transport. This is even more significant for those in lockdown in places further away from the clinic than their usual work or residences.

(iii) The reduced use of public transport also lowers patients' risk of COVID-19 infection and/or transmission.

(iv) The opportunity cost of waiting for medication at health facilities may be high in the South African (SA) context. Patients waiting at health facilities sacrifice time that could be spent on more productive activities, such as employment, education or caregiving. Home deliveries eliminate this opportunity cost.

(v) Regular contact with the same CHW will establish continuity of care for patients.

(vi) Due to the above $(i-v)$, adherence to treatment may improve, with resultant improved health outcomes. This will be the focus of a future study.

(vii) Medication delivery may elevate the standing of $\mathrm{CHWs}$ in the health system, as they are seen to deliver tangible value to their clients. This is important in the context of SA's progress towards universal health coverage and the important role of community-based PHC played by CHWs.

(viii) Health workers can manage patients without face-to-face contact if telehealth is used. This lowers their risk of infections such as COVID-19 and TB.

(ix) Implementing this approach on a large scale will mean less congestion at health facilities. This will alleviate the physical workload on scarce human resources for healthcare.

$(x)$ Home delivery of medication can be integrated into the solution set that CCMDD offers. Currently, some CCMDD pick-up points are at the facilities themselves (Fastlane pickups). For these patients, the home delivery mechanism would be an improvement for the patient and the facility.

(xi) Home delivery can also complement CCMDD where CHWs deliver medicine to patients in areas where CCMDD has no coverage, or to patients who have opted not to use CCMDD, or who do not qualify for CCMDD for non-clinical reasons.

In Table 4, we list some of the risks and mitigation strategies for the project. Not all of the listed risks have occurred as yet, but they remain on the teams' radar in case they do.

\section{Conclusion}

We believe that this study has shown the potential for home delivery of chronic medication as an option for those patients who could not use CCMDD or were not enrolled on CCMDD at the start of lockdown, or as an additional stream to CCMDD. There

\begin{tabular}{|c|c|}
\hline Risk & Mitigation strategy \\
\hline Medication lost or stolen & $\begin{array}{l}\text { SOPs that detail controls in place, such } \\
\text { as signatures for parcels transported and } \\
\text { delivered. }\end{array}$ \\
\hline $\begin{array}{l}\text { Patients or designated } \\
\text { relatives not found, } \\
\text { leading to failed delivery }\end{array}$ & $\begin{array}{l}\text { Telephonic confirmation of pending } \\
\text { deliveries; return of undelivered parcels } \\
\text { and follow-up tracing. }\end{array}$ \\
\hline $\begin{array}{l}\text { Excessive cost of } \\
\text { transporting medication } \\
\text { where Uber is used } \\
\text { (currently ZAR35 per } \\
\text { parcel delivered) }\end{array}$ & $\begin{array}{l}\text { By scaling up to include more patients, } \\
\text { costs will fall dramatically. Transportation } \\
\text { costs will be funded by Uber and BMGF } \\
\text { until December } 2020 \text {, after which the } \\
\text { costs will need to be absorbed. The } \\
\text { experience in the Cape Metro has shown } \\
\text { that incremental costs are less than ZAR1 } \\
\text { per patient package in the first } 2 \text { months, } \\
\text { when the project is suitably scaled. }\end{array}$ \\
\hline $\begin{array}{l}\text { Medical errors due to } \\
\text { the nature of remote } \\
\text { consultations }\end{array}$ & $\begin{array}{l}\text { File audit, peer review and supervision by } \\
\text { family physician. }\end{array}$ \\
\hline $\begin{array}{l}\text { Incorrect medication } \\
\text { dispensed or delivered to } \\
\text { patients }\end{array}$ & $\begin{array}{l}\text { Pharmacist supervision. Patients given a } \\
\text { number to phone if they note any errors } \\
\text { in the medication. }\end{array}$ \\
\hline
\end{tabular}

is an opportunity to expand the option of home delivery of medications to all PHC clinics and CHCs in Tshwane, starting with those with the highest headcounts and the highest numbers of missed appointments. This will assist in strengthening CCMDD enrolment and delivery through telephonic consultations and registering ward-based outreach team (WBOT) health posts as pick-up points. If up to one-third of clients are eligible for home delivery, this could alleviate a very substantial burden on the health system during a time when there are new pressures. This may further improve networking between Tshwane health facilities and non-governmental organisation partners to make more resources available for decongestion of facilities and tracing patients who missed appointments. Finally, on taking a patientcentric view of healthcare delivery, the early feedback indicates that this should be a service that continues beyond the current COVID-19 crisis period.

Acknowledgements. We thank Nicoleen Smit (Department of Family Medicine research technician) for manuscript preparation, and Mr Ofentse Mathibe for managing the Qualtrics and Uber Technologies accounts.

Author contributions. BR, SN and JML implemented the project. DB and JML wrote the article. CC, JW and ZB took part in analysis and writing of the article. JML analysed the data. SN designed the data collection tools. $J H, M L, S S, P M$ and MM provided oversight, support and advice in the implementation of the project.

Funding. Uber provided credit for the transport of medication to the WBOTs. The Department of Family Medicine of the University of Pretoria provided administrative and logistical support.

Conflicts of interest. None. 
1. Guan W-jie, Liang W-hua, Zhao Y, et al. Comorbidity and its impact on 1590 patients with COVID-19 in China: A nationwide analysis. Eur Respir J 2020;55(5):2000547. https://do org/10.1183/13993003.00547-2020

2. Kluge HHP, Wickramasinghe $\mathrm{K}$, Rippin $\mathrm{HL}$, et al. Prevention and control of noncommunicable diseases in the COVID-19 response. Lancet 2020;395(10238):1678-1680 https://doi.org/10.1016/s0140-6736(20)31067-9

3. Williamson EJ, Walker AJ, Bhaskaran K, et al. OpenSAFELY: Factors associated with COVID-19 death in 17 million patients. Nature 2020;(epub ahead of print). https://doi. org/10.1038/s41586-020-2521-4

4. Shange N. Almost 11000 HIV-positive patients in Gauteng have skipped ARV collection during lockdown. Times Live 19 May 2020. https://www.timeslive.co.za/news/southafrica/2020-05-19-almost-11000-hiv-positive-patients-in-gauteng-have-skipped-arvcollection-during-lockdown (accessed 29 June 2020).
5. Human Sciences Research Council. HSRC study on COVID-19 indicates overwhelming compliance with the lockdown. Cape Town: HSRC, 2020. http://www.hsrc.ac.za/en/ media-briefs/general/lockdown-survey-results (accessed 29 June 2020).

6. Tshwane Health District. District Health Plan 2019 - 2020. Tshwane: Tshwane Health District, 2019

7. District Health Information System. Pretoria. Pretoria: DHIS, 2020

8. Western Cape Government. New Healthbot launched for high-risk patients during COVID-19. Cape Town: WC Government, 2020. https://www.westerncape.gov.za/news/ new-healthbot-launched-high-risk-patients-during-covid-19 (accessed 29 June 2020).

Accepted 23 July 2020. 